\title{
Infográfico: características, autoria e uso educacional
}

\author{
Valéria Machado da $\operatorname{Costa}^{1}$ \\ Liane Margarida Rockenbach Tarouco ${ }^{2}$
}

Resumo. A convergência digital, um dos pilares da Sociedade da Informação, permitiu que os conteúdos educacionais desenvolvidos passassem a utilizar diferentes mídias de forma integrada. O formato infográfico é uma destas possibilidades que permite integrar texto e imagens em coerência com a Teoria da Aprendizagem Multimídia. Este artigo analisa as características e uso educacional de infográfico para sua autoria através do uso integrado de Javascript com um software que facilita a criação de imagens com links associados a segmentos (Mapedit). Um template desenvolvido para facilitar a produção de infográficos para fins educacionais é apresentado e descrito.

Palavras-Chave: infográfico; aprendizagem multimídia; conteúdo educacional multimídia

\begin{abstract}
Digital convergence, one of the pillars of the Information Society, allowed the educational content developed passed to use different media in an integrated manner. The format infographic is one those possibilities that lets you integrate text and images consistent with the Multimedia Learning Theory. This article analyzes the characteristics and educational use of infographics for his authorship through JavaScript integrated with software that facilitates the creation of images with links to associated segments (Mapedit). A template developed for facilitate the production of infographics is presented for educational purposes and described.
\end{abstract}

Keywords: infographic; multimedia learning; multimedia educational content

\section{Introdução}

A Sociedade da Informação está baseada em três pilares: a convergência digital, a dinâmica da indústria e o crescimento da Internet (TAKAHASHI, 2000). A convergência digital permitiu que toda a informação pudesse ser armazenada, representada e transmitida de forma digital, favorecendo a combinação de diferentes matrizes de linguagem, ou seja, texto, imagem e som.

Dessa forma, a integração digital possibilita e demanda novas estratégias no uso combinado de mídias para a criação de conteúdo digital e, em especial, oportuniza novas alternativas para a produção de material educacional multimídia. A possibilidade de integração de som, imagem estática, imagem em movimento, texto, entre outras mídias, abre um vasto campo de exploração para professores que desejam produzir seu próprio conteúdo.

\footnotetext{
${ }^{1}$ Doutoranda em Informática na Educação PGIE-UFRGS. Email: costavm@gmail.com

2 Professora CINTED-UFRGS e PGIE-UFRGS. Email: liane@ penta.ufrgs.br
} 
Um dos formatos digitais que vem sendo bastante utilizado na área de comunicação, mas ainda pouco explorado na educação, é o infográfico. Um estudo sobre as características deste tipo de recurso mostrou que seu uso educacional é apropriado e recomendado, existindo teorias de aprendizagem multimídia que fornecem subsídio teórico apropriado para apoiar a análise educacional deste recurso (MAYER, 2005).

A partir dos estudos preliminares que evidenciaram as vantagens do uso educacional de infográficos foi investigada a questão da autoria e neste sentido algumas ferramentas foram inspecionadas com vistas a determinar se ofereciam funcionalidades adequadas para a autoria de infográficos educacionais e se tinham baixo nível de complexidade associado ao seu uso, uma vez que a meta da pesquisa era encontrar uma solução que pudesse ser amplamente usada por professores com nível básico de alfabetização digital (capazes de usar ferramentas de edição e formatação básica de texto com imagens) sem formação específica em computação (TAROUCO, 2007).

Os pontos básicos desta pesquisa envolveram e consideraram: i) o subsídio teórico encontrado na Teoria da Aprendizagem Multimídia desenvolvida por Mayer (2005; 2009); ii) a possibilidades de incluir no infográfico interatividade e multimidialidade tal como vem sendo usado no jornalismo on-line (PALÁCIOS, 2003) e iii) uma solução para a autoria de infográficos de forma fácil e rápida utilizando uma combinação do software Mapedit e de Javascript.

A pesquisa foi também motivada pelo fato de que o uso educacional do formato infográfico com multimídia leva em conta os processos cognitivos do aprendiz ao lidar com conteúdo multimídia e que desenvolver tais habilidades é importante na preparação do estudante para atuar como cidadão na Sociedade da Informação.

A apresentação do trabalho desenvolvido e dos resultados alcançados até o momento incluem uma apresentação de infográfico e apresentação de suas características quando em formato digital bem como suas potencialidades educacionais (seção 2), seguida de discussão sobre o uso educacional com base na Teoria da Aprendizagem Multimídia (seção 3). Possibilidades de uso de recursos simples de software para produção de infográficos com fins educacionais de modo que esta autoria possa ser feita por educadores sem conhecimento especializado de informática são também descritas (sessão 5) seguidas de comentários e considerações finais (sessão 5).

\section{O infográfico}

Infografia ou infográficos são representações visuais de informação. Esses gráficos são usados onde a informação precisa ser explicada de forma mais dinâmica, como em mapas, jornalismo e manuais técnicos, educativos ou científicos. Pode utilizar a combinação de fotografia, desenho e texto. Um exemplo de infográfico do tipo mais simples poderia ser uma linha de tempo onde, ao selecionar determinados períodos, apareceriam imagem e textos explicativos.

A inter-relação texto e imagem não é algo novo. Em uma cultura da convergência, na qual os alunos convivem com interfaces audiovisuais desde cedo (por meio da TV, do videogame e da própria internet), seria esperável um uso integrado mais intenso de imagens, e outras mídias, na área da educação.

No entanto, muitos conteúdos educacionais multimídia são na verdade uma justaposição de mídias (SALAVERRÍA, 2005), isto é, não há uma integração entre as 
mídias que compõem aquele conteúdo ou mesmo uma escolha adequada em relação à mídia a ser utilizada ou a combinação de mídias mais apropriada.

Frente a esta constatação, cabe investigar e incentivar o uso de alternativas que a tecnologia enseja para combinar de forma mais integrada recursos multimídia, e que têm sido usados na área da comunicação social, mais precisamente no jornalismo, como o formato infográfico. Geralmente utilizado em matérias de cunho científico e tecnológico, seu principal objetivo é tornar claro um assunto para leitores iniciantes no assunto (CAIRO, 2008). Segundo Valero Sancho (2000), a infografia pode ser definida como:

uma contribuição informativa, feita no jornal impresso, realizada com ícones e elementos tipográficos, que permite ou facilita a compreensão das ações ou temas da atualidade ou alguns dos seus aspectos mais importantes e acompanha ou substitui o texto informativo. (SANCHO apud CAIRO, 2008, p. 21).

Para Colle (1998), a infografia é um novo tipo de "discurso" que, quando bem construído, "mescla texto e ilustração em uma unidade de espaço autosuficiente em sua capacidade de informar". Neste caso, poderíamos dizer que houve uma integração entre as mídias texto e imagem. Ainda, segundo o autor, há uma complementação entre as linguagens verbal e visual, uma vez que a primeira é "analítica: divide e compara, em etapas que se sucedem no tempo, e a compreensão surge do estudo das partes e da apreensão de seus sentidos"; e a segunda é mais sintética, uma vez que pela "visão é possível perceber uma forma significativa em sua globalidade".

No entanto, cabe destacar que uma infografia não é considerada como tal por ser publicada em um jornal ou qualquer outro meio impresso. Qualquer informação apresentada na forma de diagrama (uma representação abstrata da realidade) é uma infografia ou uma visualização da informação (CAIRO, 2008).

Assim, a infografia torna possível transformar dados sem sentido em informações organizadas de forma que o leitor/aluno possa entendê-las (como mostrado na Figura 1), sendo um dos formatos possíveis dentro do campo de investigação conhecido como visualização da informação.

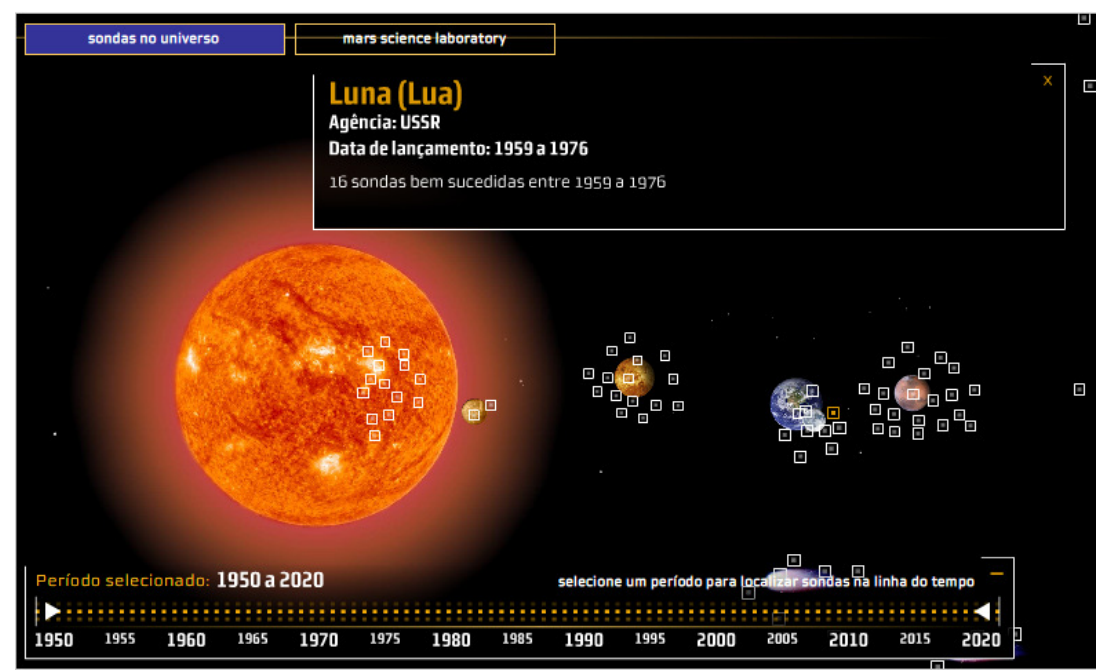

Figura 1. Infográfico sobre sondas no universo

Fonte: http://super.abril.com.br/multimidia/info_345143.shtml 
Segundo Freitas et al (2001), na visualização da informação o objetivo é representar graficamente dados de uma área de domínio de modo que esta representação visual explore a capacidade de percepção do leitor e que este possa não só interpretar e compreender as informações dadas, mas também deduzir novas informações.

Uma outra definição que mostra o quanto esta área é próxima da educação, embora seja pouco explorada no formato digital, é a de Ware (2004 apud DIAS, CARVALHO, 2007) para quem a visualização da informação é uma "ciência que está presente desde a necessidade anterior das áreas de Física e Química para representar fenômenos em esquemas, desenhos e esboços". Ou seja, a visualização da informação seria especialmente útil para conteúdos que demandassem alguma forma de organização/apresentação além do texto escrito para uma melhor compreensão.

Nesse sentido, o suporte digital não só facilitou o desenvolvimento de novos formatos de apresentação da informação como também trouxe outras possibilidades, como o uso de hiperlinks, a interatividade e o uso de várias mídias, além do texto e imagem do suporte impresso. Estes elementos, se bem aplicados, podem contribuir significativamente para o processo de ensino-aprendizagem, pois o ser humano naturalmente apropria e processa simultaneamente mais de uma forma de mídia e a integração entre as mesmas pode ser diferencial entre um resultado que seja uma cacofonia dissonante cognitivamente ou um elemento alavancador da aprendizagem.

\subsection{O infográfico online}

Enquanto o suporte impresso é fixo, estável, o suporte digital é fluido e líquido. Dessa forma é possível que cada leitor do infográfico trilhe a sua própria busca de informação, pautando-a de acordo com suas preferências e necessidades. Neste caso, a infografia pode ser considerada como uma ferramenta de exploração e não apenas como uma "simples" apresentação da informação (CAIRO, 2008).

Segundo Cairo (2003 apud RIBAS, 2004):

Na infografia impressa não é possível mostrar um objeto ao mesmo tempo aberto e fechado, a menos que se tenha espaço de sobra na página, o que quase nunca ocorre. [...] Já na infografia animada podemos nos dar ao luxo de mostrar o objeto com todos os seus detalhes. Primeiro fechado: o usuário o vê tal como é por fora. Depois, aberto, com tudo o que tem por dentro. (CAIRO, 2003).

Assim, o espaço ilimitado e a possibilidade que o usuário tem de gerir seu próprio tempo trazem à infografia online novas possibilidades.

O uso de hiperlinks, por exemplo, permite que o aluno trilhe seus próprios caminhos e, à medida que vai escolhendo seu caminho, vai interagindo com o infográfico. Esta interatividade pode variar de um nível mais básico (como clicar em setas de avançar e recuar ou em botões na tela para ver determinado conteúdo) a um mais avançado (como entrar com dados, montar coisas ou simular algo).

Com relação à multimidialidade, ou multimídia, além do fato de, no suporte digital, haver a possibilidade de inserir toda e qualquer mídia, tem-se como vantagem também o fato de que, segundo Mayer (2005; 2009), as pessoas aprendem melhor através de palavras e imagens do que somente através de palavras. 


\section{Por que utilizar o infográfico: a teoria da aprendizagem multimídia}

Como uma primeira etapa para entender como o infográfico pode auxiliar o processo de ensino-aprendizagem deve-se buscar suporte em teorias cognitivas subsidiadoras.

Segundo a teoria do processamento da informação, o cérebro humano possui uma memória sensorial, responsável por captar os estímulos provenientes do meio ambiente; uma memória de curto prazo, volátil, também conhecida como memória de trabalho, que pode ser entendida, metaforicamente, como uma agência de produção multimídia que está continuamente manipulando e gerando imagens e sons que são organizados significativamente) e armazenados em uma memória de longo prazo (SWELLER, 1998). Depois de armazenadas, essas imagens e sons ainda estão disponíveis para reformulação e integração com novos conceitos, quando novas informações são recebidas. A memória de trabalho constitui um gargalo neste processo em função de sua capacidade limitada de tratamento de informações.

No caso da aprendizagem multimídia, busca-se contornar esta limitação da memória de trabalho utilizando combinação de mídias verbal e visual . Existem estudos (MILLER, 1978) que estabelecem que a capacidade de memória de trabalho, ou de curto prazo, do ser humano, pode conter, num dado instante, aproximadamente sete itens, mais ou menos dois, ou seja, pode ir de cinco a nove itens (um item pode ser um simples dígito ou uma palavra ou um agrupamento de informações). Segundo a Teoria da Carga Cognitiva (SWELLER, 1998 e PAAS, 2004),

a aprendizagem se dá de maneira melhor quando o processo de informação estiver alinhado com o processo cognitivo humano, ou seja, quando o volume de informações oferecidas ao aluno for compatível com a capacidade de compreensão humana. Assim a Teoria da Carga Cognitiva, apóia-se na impossibilidade natural do ser humano em processar muitas informações na memória a cada momento.

Por outro lado, também, embora o uso de texto tenha predominado no processo educacional por muito tempo, pesquisadores como Moreno e Mayer (2007) estudaram o impacto de modos multimodais de apresentação, especialmente os que usam palavras e imagem para representar o conhecimento porque de acordo com o princípio de aprendizagem multimídia (MAYER, 2001) a compreensão dos os estudantes pode ser aprimorada pela adição de representação não verbal do conhecimento, em adição a explicações verbais (escritas ou faladas).

Adicionalmente, Mayer propôs que o processo de apropriação de informação ocorre com tratamento em paralelo ao que é apropriado por dois canais, um visual ou pictórico e outro verbal ou auditivo, conforme a Figura 2. Esta é a Teoria da Codificação Dual de Richard Mayer (2005) que tem sido amplamente usada para nortear o projeto de conteúdo educacional multimídia. 


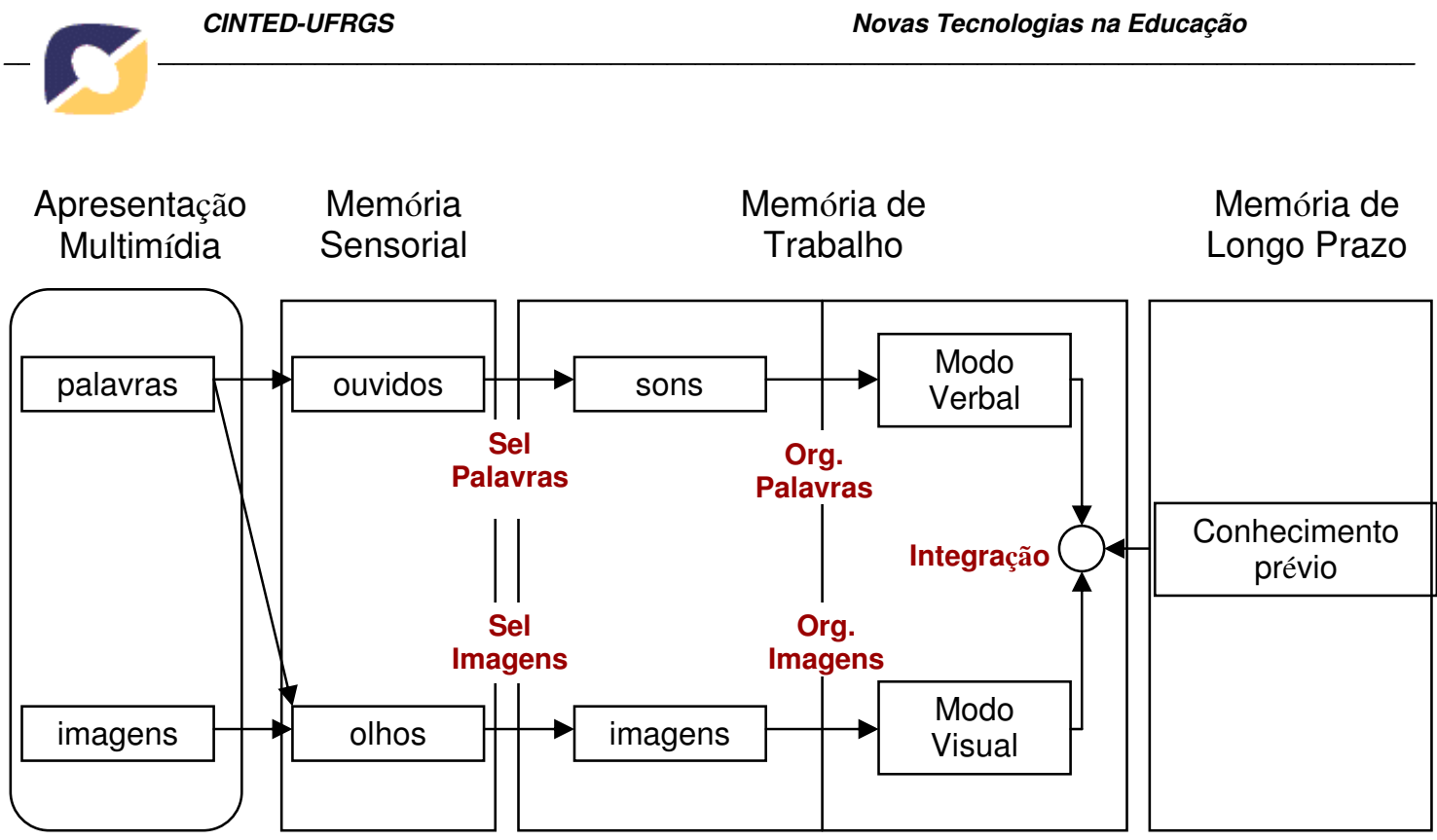

Figura 2. Processamento Dual da Informação

Fonte: Adaptado de Mayer (2005).

Em decorrência da Teoria da Codificação Dual (MAYER, 2005), deriva-se que um conteúdo educacional digital deve utilizar um modo dual de apresentação do conteúdo, isto é, um formato em que o estímulo (mídia) é apresentado, pode ser verbal ou não-verbal. Um estímulo verbal, nesta concepção, poderia ser a palavra falada ou escrita. Um estímulo não-verbal seria uma imagem, um vídeo, uma animação ou um som de fundo sem letra.

Em vista destes pressupostos, evidencia-se que o infográfico favorece a aprendizagem ao combinar harmoniosamente texto e imagem. Segundo Clark e Mayer (MAYER, 2005), as pessoas aprendem melhor com texto e imagem, uma vez que:

As apresentações multimídia podem incentivar os alunos a se empenharem na aprendizagem ativa representando mentalmente o material em palavras e imagens e fazendo conexões mentais entre as representações visuais e verbais. Por outro lado, apresentar somente palavras pode incentivar os alunos - especialmente aqueles com menos experiência ou conhecimento linguístico - a participarem superficialmente da aprendizagem, por não conseguirem conectar as palavras com conceitos e outros conhecimentos (CLARK, MAYER, 2008, p. 57).

Estas concepções corroboram o que afirma Cairo (2008) sobre a importância da infografia, principalmente para os novatos em determinado assunto. Adicionalmente, as imagens nos infográficos são fundamentais para a compreensão do conteúdo, não podendo ser selecionadas por critérios meramente decorativos, ou seja, como imagens que não contribuem para o entendimento do conteúdo (CLARK e MAYER, 2008). Essa característica do uso integrado de multimídia é salientada por Mayer $(2005,2009) \mathrm{em}$ um dos seus sete princípios para o desenvolvimento de material educacional multimídia, o princípio da coerência. Segundo ele, é necessário retirar do conteúdo educacional multimídia todos os textos, imagens, sons não relevantes para o assunto porque a presença de tais elementos pode sobrecarregar cognitivamente o aluno fazendo com que ele preste atenção em elementos irrelevantes e deixe de perceber e atentar para os relevantes. 
Um outro princípio presente nos infográficos é o da princípio da proximidade espacial (MAYER, 2005), que estabelece que quando textos e imagens estão próximos, o resultado é melhor do que quando estão afastados. Tal princípio visa evitar o efeito da atenção dividida (split attention) no aluno. Segundo Clark, Nguyen, Sweller (2006, p. 77), o "efeito da atenção dividida ocasiona aumento na carga cognitiva irrelevante que ocorre quando o estudante tem de integrar duas ou mais partes da mesma informação, mas que estão fisicamente separadas".

Segundo estes autores, ao trabalhar com um conteúdo educativo o estudante tem que processar três tipos de cargas cognitivas: i) a carga cognitiva intrínseca, que diz respeito à complexidade inerente ao conteúdo a ser ensinado; ii) a carga cognitiva natural, ou relevante, que é relativa às atividades de ensino que favorecem o objetivo da aprendizagem; e iii) a carga cognitiva externa ao conteúdo, ou irrelevante, que é aquela que não auxilia na construção e automação de esquemas, desperdiçando os recursos cognitivos limitados da memória de trabalho que poderiam, e deveriam, ser usados para a aprendizagem. As duas últimas são cargas cognitivas extrínsecas (CLARK, NGUYEN, SWELLER, 2006).

Como afirmam Sweller et al. (1998, p. 264): “A atenção do aluno deve ser afastada de processos irrelevantes para a aprendizagem e direcionada para processos que são relevantes para a aprendizagem e, em particular, para a construção e elaboração consciente de esquemas". Para isso, é preciso reduzir a carga cognitiva irrelevante, aumentar a relevante e gerenciar a intrínseca. Neste último caso, o gerenciamento é feito por meio da maior ou menor granularidade do conteúdo de acordo com o público-alvo do mesmo.

Estes subsídios reforçam a que é expresso por Cairo (2010) quando afirma que o principal objetivo de um infográfico é ajudar a cognição do leitor - levando em consideração a capacidade e limites da memória humana -, ou seja, ele deve ser elaborado para que haja uma redução de sua carga cognitiva no entendimento da informação.

Estes pressupostos teóricos reforçam a proposta de que o formato infográfico tem bom potencial para uso educacional em consonância com os princípios da Teoria da Aprendizagem Multimídia. Em vista disso, foram investigadas possibilidades em termos de ferramentas de autoria para criar infográficos e alguns resultados alcançados serão relatados na sessão seguinte.

\section{Ferramenta de autoria para criar infográficos}

Não existe uma ferramenta única para criar infográficos. De modo geral, infográficos têm sido produzidos mediante o uso de combinações de ferramentas com algum recurso adicional de programação (especialmente em Javascript) para criá-los e organizar o acesso interativo aos mesmos.

Uma ferramenta muito utilizada por profissionais atuantes em design de multimídia é o Flash (ADOBE, 2010). No entanto, a complexidade desta ferramenta de autoria dificulta seu uso por docentes que não têm fluência digital o que levou à necessidade de investigar outras opções mais simples, mesmo que um tanto mais limitadas do que o Flash.

Uma destas opções consiste em usar uma combinação do software Mapedit com o Javascript. O software Mapedit (BOUTELL, 2010) é utilizado para criar mapas 
sensíveis. Um mapa sensível é uma imagem ou gráfico incluído em uma página WWW, juntamente com controles ou tags HTML do tipo map, de modo que um usuário pode clicar em áreas diferentes da imagem e isto levar a percorrer links diferentes ou a invocar scripts (Javascript) específicos. Este software permite selecionar e indicar de forma simplificada as coordenadas que delimitam as áreas a serem associadas com endereços de páginas que deverão ser invocadas quando o usuário clicar naquela parte da imagem. Esta definição dos pontos delimitadores das áreas sensibilizadas da imagem pode ser feita diretamente em HTML incluindo-se os tags "map" apropriados, mas é um processo trabalhoso e propenso a erros. Adicionalmente, podem ser usados outros editores para produzir as informações e controles a serem usados com imagens sensibilizadas. O software livre GIMP é um exemplo de editor de imagem que indica as coordenadas de cada ponto de imagem ao se passar o mouse sobre estes pontos e desse modo tais dados poderiam ser incluídos no tag "map" para delimitar as áreas. Mas neste trabalho optou-se por explorar a opção de uso do Mapedit que tem custo bastante reduzido e oferece recursos para incluir alguns comandos Javascript a serem incluídos na página de apresentação da imagem para permitir obter o efeito de interatividade no infográfico.

No modo normal de uso do recurso de imagem sensibilizada, quando uma área em uma imagem é definida, é associado um hiperlink a ela. Posteriomente, ao ser exibida a página com esta imagem e os controles "map" inerentes, ao ser clicada aquela área, será aberta uma nova janela para exibição do conteúdo contido na página chamada, ou seja, não é possível manter visível na mesma página, simultaneamente, a imagem sensibilizada e os conteúdos associados com as áreas sensibilizadas. Com base na Teoria da Aprendizagem Multimídia, tal forma de apresentação não está de acordo com o princípio da contigüidade espacial, o que pode gerar o efeito de split attention, uma vez que o aluno teria de ficar mudando de uma página para outra para integrar, em sua memória de trabalho, os dois elementos.

Para solucionar este problema, buscou-se uma forma de contornar esta dificuldade e a estratégia delineada implica no uso do Mapedit para mapear a imagem e gerar as coordenadas que serão posteriormente copiadas e usadas juntamente com Javascript. Para facilitar esta forma de uso, foi criado um template que está disponível para acesso e download no endereço indicado abaixo neste artigo ${ }^{3}$. Neste sentido o professor interessado em utilizar a estratégia proposta, pode utilizar o template aqui sugerido como ponto de partida para a criação de seu infográfico.

O primeiro passo é baixar o programa Mapedit ${ }^{4}$ (que é gratuito até 100 gravações), fazer upload da imagem que será a base do infográfico e selecionar as áreas sensíveis que serão associadas a imagens ou textos. É possível marcar imagens nos formatos: retângulo, círculo e polígono.

No exemplo da Figura 3, foi utilizado o mapa do Brasil e foram sensibilizadas as áreas correspondentes aos estados que formam a região Sul do país.

\footnotetext{
${ }^{3}$ Disponível em: http://infograficonaeducacao.pbworks.com/w/page/FrontPage. Acesso em: 16 out. 2010.

${ }^{4}$ http://www.boutell.com/mapedit/download.html. Acesso em: 16 out. 2010.

V. $8 \mathrm{~N}^{\mathrm{o}} 3$, dezembro, 2010
} 


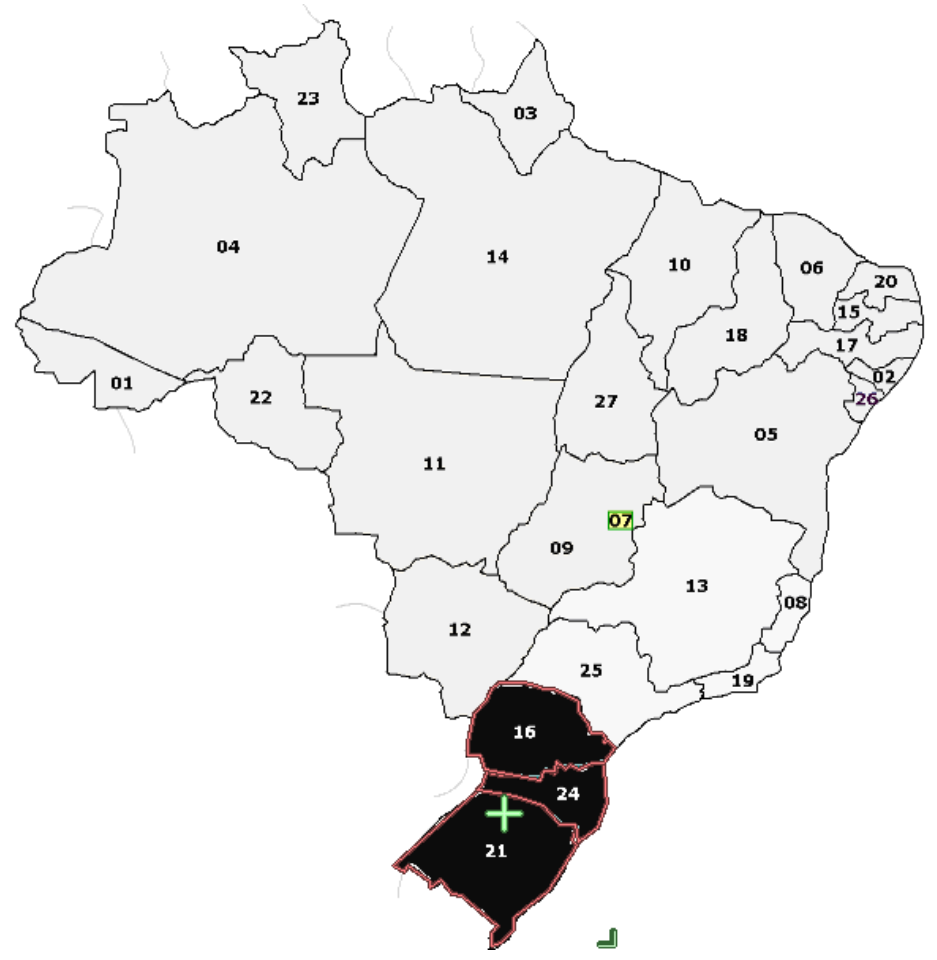

Figura 3. Áreas mapeadas no software Mapedit

Após marcar cada área, surge uma caixa de diálogo na qual o professor deve inserir o texto que vai aparecer quando o aluno passar o cursor sobre aquela área (esse texto pode ser inserido na opção ALT). Em seguida, nos casos de áreas que vão abrir um texto ou imagem, o professor deve colocar, nas opções onMouseOver e onMouseOut algum texto que será depois substituído no template. A Figura 4 demonstra este passo da criação de um infográfico que combina tags HTML "map" e Javascript. 


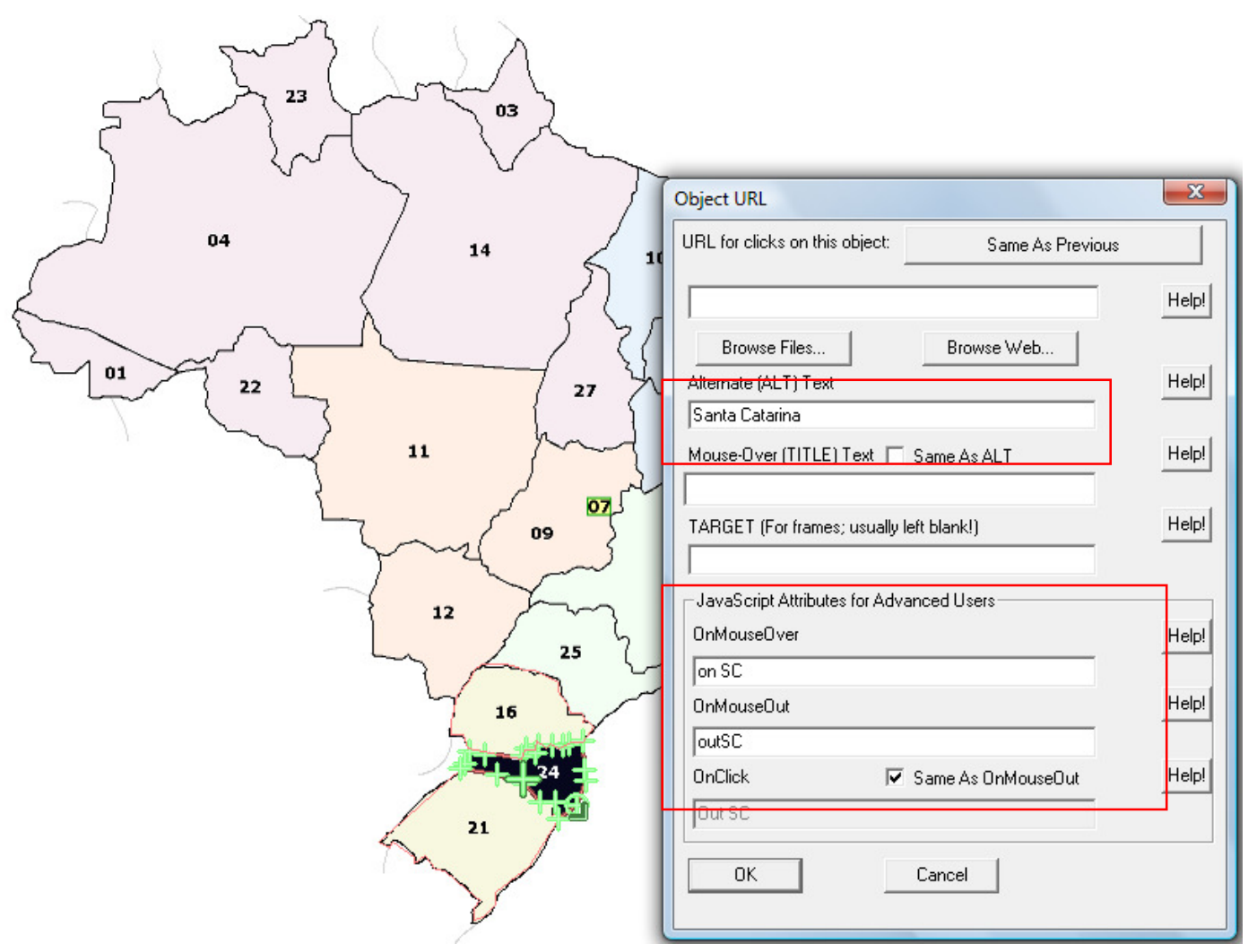

Figura 4. Campos a serem preenchidos pelo professor

Após mapear cada área e preencher os campos mostrados na Figura 4, o professor deve salvar o arquivo com a extensão .html.

Em seguida, deve abrir este arquivo no bloco de notas e copiar todo o conteúdo que está entre as tags $\langle$ body $>$ e $</$ body $>$, como mostrado na Figura 5. Note que há várias coordenadas porque foi utilizado o formato polígono para delimitar cada área sensibilizada na imagem. Caso sejam utilizados os formatos retângulo ou círculo, a quantidade de coordenadas é reduzida.

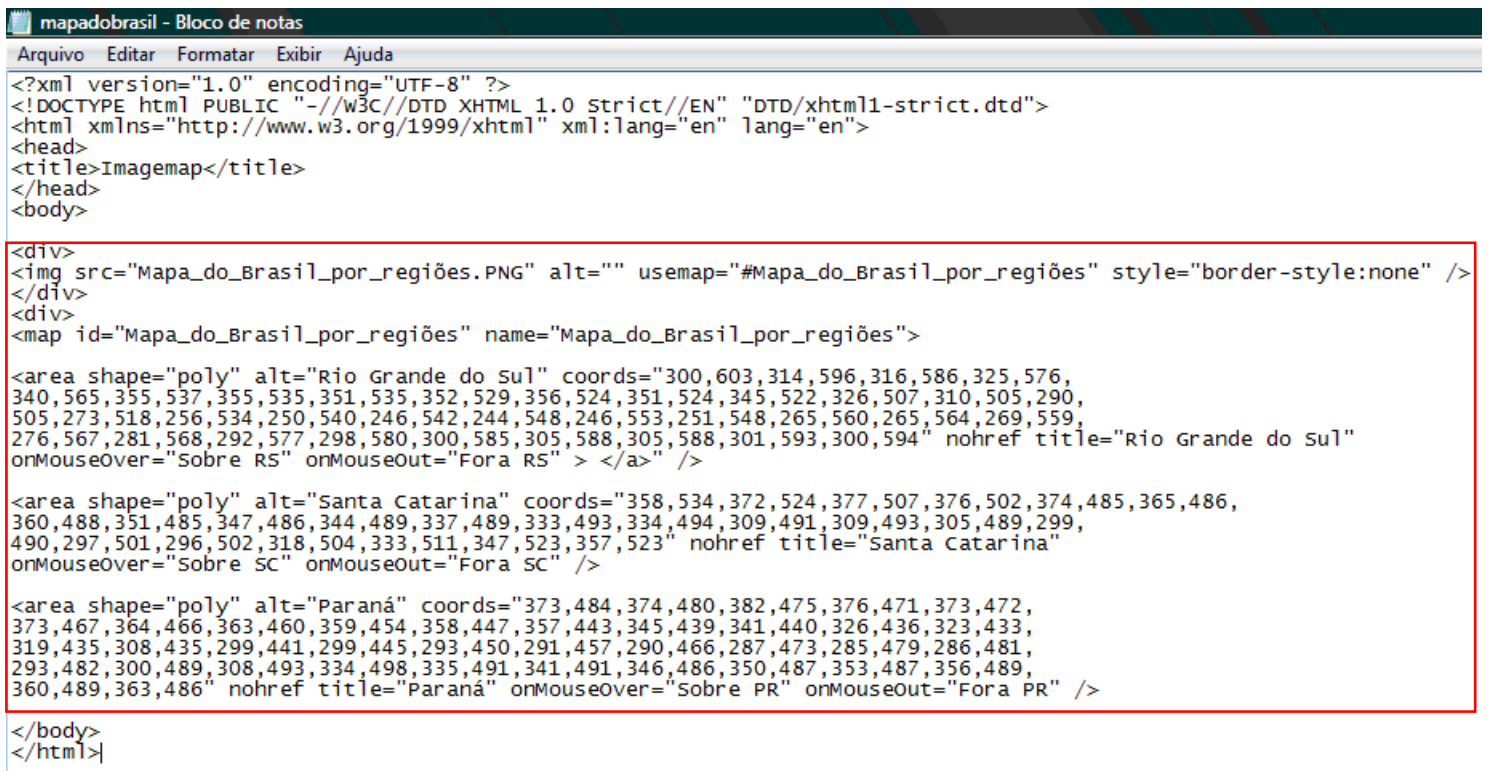

Figura 5. Código a ser copiado 

do Mapedit.

Essa parte deve ser colada no template onde está indicada a parte que foi copiada

Em seguida, deve-se substituir os textos entre aspas dos comandos onMouseOver e onMouseOut. No caso de abrir uma imagem, substitua:

$$
\text { onMouseOver="Sohre RS" onMouseOut="Fora RS" }
$$

Por:

onMouseOver="document.imagem.src=imagem 1. src"

onMouseOut="document.imagem.src=imagem0.src"

As imagens indicadas são as que devem ser exibidas: imagem1 deve aparecer quando o aluno passar o mouse sobre o estado do Rio Grande do Sul; imagem0 deve aparecer quando o aluno retirar o mouse desta parte da figura.

Essa associação deve ser feita no início do template com os arquivos que serão utilizados pelo professor:

$$
\begin{aligned}
& \text { imagem0.src="blank.jpg" } \\
& \text { imagem1.src="mapariograndedosul3.jpg" }
\end{aligned}
$$

A Figura 6 mostra o exemplo de nosso template quando o usuário passa o mouse sobre o estado do Rio Grande do Sul:

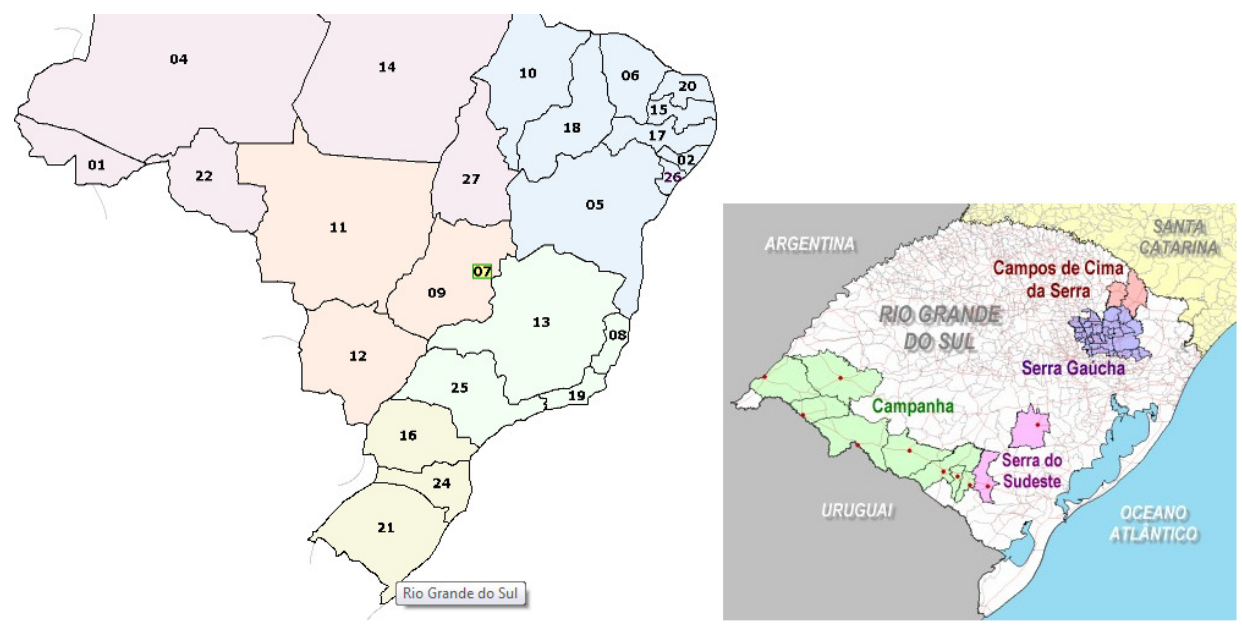

Figura 6. Exemplo de associação com imagem

Caso o professor queira associar um texto à área sensível, deve trocar:

$$
\text { onMouseOver="Sobre SC" onMouseOut="Fora SC" }
$$

Por:

$$
\begin{aligned}
& \text { onMouseOver="insere();" } \\
& \text { onMouseOut="limpa();" }
\end{aligned}
$$

Além disso, deve digitar o texto a ser exibido na tela entre as aspas do comando txt=" ", logo depois da função insere (), como mostrado na Figura 7. 
function insere() \{

$\langle!--v a r i a ́ v e l$ txt. Digite aqui o texto a ser exibido -->

txt="Os 500 quilômetros de litoral são um paraíso para quem busca belas praias e o contato com a natureza.

Esta região, colonizada por açorianos no século XVIII, tem um relevo recortado, com baías, enseadas, manguezais, lagunas e mais de 500 praias. É, ainda, uma das mais importantes áreas de biodiversidade marinha do Brasil.

Fonte: http://ww.sc.gov.br/conteudo/santacatarina/geografia/paginas/regioes.htm"

Figura 7. Área do template onde o texto deve ser inserido

A Figura 8 mostra como o texto digitado aparece na tela em nosso template.

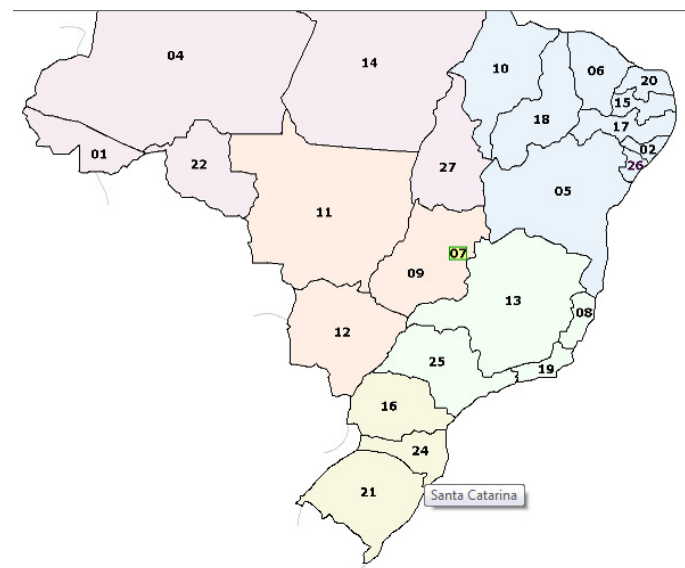

Os 500 quilômetros de litoral são um paraíso para Esta regiăo, colonizada por açorianos no século xVIII, tem um relevo recortado, com baias, enseadas, mangueza1s, lagunas e mais de 500 praias. É, aind marinha do Brasil. Fonte: http://www.sc.gov.

\section{Figura 8. Exemplo de associação com texto}

Com essas simples modificações é possível reutilizar o template para diferentes infográficos, de modo que cada professor possa criar um conteúdo educacional adequado às suas necessidades.

\section{Considerações Finais}

A convergência das mídias permitiu que novos formatos para conteúdos educacionais fossem criados ou adaptados ao suporte digital. Esses formatos devem ser utilizados pelos professores na criação de seus conteúdos de modo a melhorar o processo de ensino-aprendizagem.

O infográfico, além de ser um formato adequado à narrativa digital, constitui uma forma de possibilitar este uso integrado de texto e imagem tal como preconizado pela Teoria da Aprendizagem Multimídia.

Neste trabalho foi apresentada uma estratégia para que um professor, com pouco conhecimento de informática e programação, possa criar seus próprios infográficos utilizando uma ferramenta online e a linguagem Javascript através de um template. A busca de uma estratégia que apóie a autoria de infográficos pelos próprios professores e mesmo pelos alunos, apóia-se também no princípio da aprendizagem ativa ensejando a criação de recursos educacionais digitais com interatividade. Criando seus próprios conteúdos educacionais digitais interativos, os professores podem conseguir conteúdos mais integrados e adaptados ao seu contexto educacional. O compartilhamento de tais recursos, através de repositórios de conteúdo educacional aberto permitirá acesso, uso e adaptação dos infográficos por outros professores mediante o uso de conhecimento relativamente simples tal como explanado neste trabalho. 
$\mathrm{Na}$ continuação do trabalho desenvolvido, serão investigadas outras alternativas para apoiar a criação de infográficos que também ofereçam uma forma simplificada de utilização pelos professores autores e com custo reduzido.

\section{Referências}

ADOBE. Software Adobe Flash Professional CS5. Disponível em: http://www.adobe.com/br/products/flash/whatisflash/ . Acesso em: 20 set. 2010.

BOUTELL. Mapedit. Disponível em http://www.boutell.com/mapedit/. Acesso em: 20 set. 2010.

CAIRO, Alberto. Infografia 2.0: visualizacion interactiva de informacion en prensa. Espanha: Alamut, 2008.

La beleza de la simplicidad: el poder de la infografia en la era de los datos. jul. 2010. Disponível em: http://infografiaembasededados.files.wordpress.com/2010/07/ aprsentacao-alberto-cairo.pdf. Acesso em: 2 ago. 2010.

CLARK, R. C., MAYER, R. E. E-learning and the science of instruction: proven guidelines for consumers and designers of multimedia learning. San Francisco: Pfeiffer, 2008 .

CLARK, R., NGUYEN, F. SWELLER, J. Efficiency in learning: evidence-based guidelines to manage cognitive load. San Francisco: Pfeiffer, 2006.

COLLE, R. Estilos o tipos de infográfos. (1998) Revista Latina de Comunicación Social, n. 12, dezembro de 1998. Disponível em: <http://www.ull.es/publicaciones/latina/a/02mcolle/texto.colle.htm>. Acesso em: 6 ago. 2010.

DIAS, Mateus Pereira; CARVALHO, José Oscar Fontanini de. (2007) A visualização da informação e sua contribuição para a Ciência da Informação. DataGramaZero Revista de Ciência da Informação. v. 8, n. 5, out. 2007. Disponível em: dgz.org.br/out07/Art_02.htm. Acesso em: 6 ago. 2010.

FLETCHER, J. D., TOBIAS, S. The multimedia principle. In: MAYER, R. E. (Ed.). The Cambridge Handbook of Multimedia Learning. New York: Cambridge University Press, 2005. p. 117-134.

FREITAS, C. M. D. S. et al. Introdução à Visualização de Informações. RITA Revista de Informática Teórica e Aplicada, Instituto de Informática UFRGS, Porto Alegre, RS, v. VIII, n. 2, p. 143-158, outubro, 2001. Disponível em http://www.inf.ufrgs.br/ revista/docs/rita08/ rita_v8_n2_p143a158.pdf. Acesso em: 12 maio 2007.

MAYER, R. E. Introduction to Multimedia Learning. In: MAYER, R. E. (Ed.). The Cambridge Handbook of Multimedia Learning. New York: Cambridge University Press, 2005. p.1-18.

Multimedia Learning. New York: Cambridge University Press, 2009.

MILLER, G. A. The magical number seven, plus or minus two: some limits on our capacity for processing information. Psychological Review, 1978, v. 63, p. 81-97. http://www.well.com/user/smalin/miller.html. Acesso em: 21 jan. 2003. 
MORENO,R. Mayer, R. Interactive Multimodal Learning Environments. Educ Psychol $\operatorname{Rev}(2007)$ 19:309-326

PAAS, F. RENKL, A. Sweller, J. Cognitive Load Theory: Instructional Implications of the Interaction between Information Structures and Cognitive Architecture. Instructional Science 32: 1-8, 2004.

PALACIOS, M. Ruptura, continuidade e potencialização no jornalismo on-line: o lugar da memória. In: MACHADO, E.; PALACIOS, M. (Orgs.). Modelos de jornalismo digital. Salvador: Edições GJOL; Calandra, 2003, pp. 13-36.

RIBAS, B. Infografia Multimídia: um modelo narrativo para o webjornalismo. In: V Congreso Iberoamericano de Periodismo en Internet, Salvador, 2004. Disponível em: http://www.facom.ufba.br/jol/pdf/2004_ribas_infografia_multimidia.pdf. Acesso em: 06 ago. 2010.

SALAVERRÍA, R. Redaccion periodística en internet. Navarra: EUNSA, 2005.

SWELLER, J. et al. Cognitive architecture and instructional design. Educational Psychology Review. v. 10, n. 3, 1998.

TAKAHASHI, T. (Org.). Sociedade da informação no Brasil: livro verde. Brasília: MCT, 2000.

TAROUCO, Liane; AVILA, Bárbara Multimídia na alfabetização digital com fluência para a autoria. RENOTE. Vol. 5, No 2 (2007). 